\title{
The GABA Antagonist Picrotoxin Attenuates an Ethanol-Induced Taste Aversion in Taste Aversion-Prone Rats
}

\author{
Joseph Tkacz ${ }^{1}$, Stephen Hobbs ${ }^{2}$, Ralph Elkins ${ }^{3}$ \\ ${ }^{1}$ Health Analytics, Columbia, USA; ${ }^{2}$ Department of Psychology, Augusta State University, Augusta, USA; ${ }^{3}$ Schick Shadel Hospital, \\ Seattle, USA. \\ E-mail: joseph.tkacz@healthanalytic.com
}

Received October $10^{\text {th }}, 2011$; revised November $17^{\text {th }}, 2011$; accepted November $28^{\text {th }}, 2011$.

\begin{abstract}
The aversive properties of alcohol can be examined by using ethanol as a conditioning agent in a taste aversion (TA) paradigm. However, there is often variability in how organisms respond to the aversive properties of alcohol. Using a selectively bred line of TA-prone (TAP) rats, the present study sought to determine if antagonizing the GABA receptor complex with picrotoxin could block the acquisition of an ethanol-based conditioned aversion to a normally preferred fluid. Fifty TAP rats were randomly divided into 5 groups. In the two experimental groups, rats were pretreated with i.p. injections of low or high doses of the $G A B A_{A}$ antagonist picrotoxin prior to undergoing taste aversion conditioning - wherein consumption of a novel saccharin solution ( $0.1 \%)$ was followed by an i.p. injection of ethanol (1.5 $\mathrm{mg} / \mathrm{kg})$. In the primary control group, rats were treated identically, except that isotonic saline was substituted for picrotoxin. In the non-conditioning and pseudo-conditioning control groups, rats did not receive an ethanol-saccharin pairing but did receive a picrotoxin injection. Repeated measures ANOVA revealed that animals in the picrotoxin groups displayed significantly weaker TAs than the primary control group $(p<0.01)$, but were not different from the non-conditioning and pseudo-conditioning groups $(p>0.05)$ as measured by post-conditioning, two-bottle saccharin preference scores. Picrotoxin hinders the acquisition of an ethanol-induced TA, thereby supporting the hypothesis that the GABA system plays a central role in ethanol's motivational effects. Possible mechanisms include 1) picrotoxin attenuates negative effects of ethanol, 2) picrotoxin interferes with the central associative processes that promote TA conditioning or 3) some combination of 1 and 2 .
\end{abstract}

Keywords: Conditioned Taste Aversion, Ethanol, GABA, Picrotoxin, Rats

\section{Introduction}

The intoxicating effects of alcohol and other recreational drugs are perceived differently by different users [1-3]. This seems to be particularly true in context of the rewarding and aversive effects of alcohol. The sheer number of people who abuse alcohol in the US [4] provides evidence of its rewarding effects. However, studies have also demonstrated that alcohol can have aversive properties [5]. The mechanisms underlying these bidirectional effects are still unknown, but two unique lines of selectively bred rats are well suited for investigation of this topic.

Lines of taste aversion (TA)-prone (TAP) and TA-resistant (TAR) rats have been selectively bred from Spra-
gue-Dawley derived albino rats. These two lines were established for use in studies of genetic contributions to individual differences in conditionability during nausea-based aversion therapies for alcohol dependence [6]. Rats of the parental and subsequent generations underwent classic TA learning, wherein a saccharin solution was paired with cyclophosphamide-a nausea inducing agent. Rats that acquired strong TAs were mated together, as were those which displayed weak TA acquisition. The selective breeding process across generations quickly produced two distinct lines of TAP and TAR rats.

A conditioned taste aversion (CTA) can be readily established when an ethanol injection is substituted for cyclophosphamide, or some other emetic class agent, as the unconditioned stimulus (UCS). The TAP and TAR 
differences in TA conditionability were maintained with an ethanol UCS [7]. Moreover, TAR rats freely self-administer considerably more ethanol than TAP rats [8]. Ethanol's differential oral acceptability and efficacy as a TA conditioning agent in TAP and TAR rats are not well understood. However, differences in ethanol metabolism, simple learning differences, and general consummatory behavior have been ruled out $[8,9]$. Thus, these lines serve as an appropriate animal model for studies of the underlying mechanisms of alcohol aversions. Studies of the TAP and TAR lines have been reviewed elsewhere [10].

TAP rats may experience ethanol as more noxious than TAR rats, perhaps due to peripheral differences in gastrointestinal distress. Alternatively, they may experience somewhat different reactions from ethanol within brain systems that subserve ethanol based TA conditionability. For example, heat shock protein 27 (HSP 27) protects against ethanol induced neurotoxicity [11]. An intraperitoneal (i.p.) ethanol injection induced an 8.8 fold marginal increase in HSP 27 gene expression in striatal tissue of TAR rats. In contrast, TAP rats displayed an opposite 11.9 fold marginal decrease in HSP 27 gene expression [12]. Reduced ethanol induced neurotoxicity via increased HSP 27 gene expression may contribute to a reduction in ethanol-based TA conditioning and an increase in oral ethanol self-administration in TAR rats. Conversely, decreased HSP 27gene expression may contribute to the TAP rats' strong ethanol induced TAs and their diminished acceptance of the oral saccharin solution.

The present study was designed to determine if antagonizing GABA, a major inhibitory neurotransmitter system that is known to be affected by ethanol [13], would influence the aversive reaction to alcohol displayed by TAP rats. Picrotoxin, described as the "prototypic antagonist" of the GABA receptor site [14], was selected as the investigative agent for its purported effect on the aversive motivational properties of ethanol [15]. Multiple studies have clearly demonstrated that picrotoxin can effectively antagonize GABA [16-19] and, at least in low doses, does not directly affect learning [20]. The CTA procedure was the selected investigational approach as it offers several advantages over other techniques (e.g. free choice ethanol acceptance)-including better control over the dose and timing of ethanol exposure, and the relatively small amounts of alcohol exposure required [15].

The only prior report of picrotoxin's effects on TA conditionability used ethanol as the UCS agent but did not study rat lines that differ in alcohol reactivity [21]. Studies of picrotoxin's effects on TA conditionability of TAP or TAR rats, given that they are selectively bred and differentially sensitive to the effects of ethanol, may advance our understanding of alcohol use disorders in humans. The findings may also facilitate the identification of alcoholics who are likely to be nefit from nauseabased TA counter conditioning treatments [22]. Based on the presumption that TAP rats have enhanced associative efficiency with respect to ethanol-induced CTAs, or that TAP rats find ethanol to be especially aversive, it was hypothesized that treating the TAP rats with picrotoxin before TA conditioning will attenuate the development of an aversion when ethanol induced CTA.

\section{Methods}

\subsection{Subjects and Housing}

The subjects were 50 TAP Sprague-Dawley derived rats bred in the animal facility at the Augusta State University's Department of Psychology. The animals were fed standard rodent blocks and were allowed to eat ad libitum throughout the course of the study. Each rat was individually housed in a standard wire-bottom cage, and testing occurred in the home cage. The colony room was maintained on a 12:12 light-dark schedule with lights on at $0600 \mathrm{EST}$ and with a controlled temperature of $23^{\circ} \mathrm{C}$ $+/-2^{\circ}$. Conditioning procedures and consummatory measures were undertaken during light-on hours (1200 - 1500 EST), a period of relatively less eating and drinking behavior. Animal care and maintenance were carried out in accordance with the Guide for the Care and Use of Laboratory Animals as adopted and promulgated by the National Institutes of Health and the EU.

\subsection{Procedure}

Animals were divided randomly into 5 experimental groups consisting of 10 animals each. The conditioning procedure for each group can be viewed in Table 1. As adapted from Elkins et al. [7], animals were fluid deprived for 24 hours prior to conditioning in order to enhance consumption of the target fluid during the conditioning procedure. Each group received a pre-conditioning injection, followed 40 minutes later by access to a specified fluid (CS). The fluid was available for at least 10 minutes and for at least 5 min after the observed onset of drinking-upon which time the bottles were removed from the cage. Approximately 5 minutes after fluid removal, each animal received a $1.5 \mathrm{mg} / \mathrm{kg}$ post-consummatory ethanol injection (UCS), or a volumetrically equivalent saline injection. Group A received the standard TA conditioning paradigm, with a saline preconditioning injection, followed by access to a $0.1 \%$ saccharin solution (CS), and then a $1.5 \mathrm{mg} / \mathrm{kg}$ ethanol injection (UCS). Groups B and C comprised the main experimental groups, with animals in Group B receiving a precon- 
Table 1. Summary of group treatments and predicted outcomes.

\begin{tabular}{lccccc}
\hline \multicolumn{1}{c}{ Group } & $\begin{array}{c}\text { Pre-Consummatory } \\
\text { Injection }\end{array}$ & Forced Drink (CS) & $\begin{array}{c}\text { Post-Consummatory } \\
\text { Injection (UCS) }\end{array}$ & Dependent Variable & Hypothesis \\
\hline A Conditioning & Saline & Saccharin & Ethanol & Two Bottle Test & Strong Aversion \\
B Low Drug Experimental & Picrotoxin $0.5 \mathrm{mg} / \mathrm{kg}$ & Saccharin & Ethanol & Two Bottle Test & Weaker Aversion \\
C High Drug Experimental & Picrotoxin $1 \mathrm{mg} / \mathrm{kg}$ & Saccharin & Ethanol & Two Bottle Test & Weaker Aversion \\
D Pseudo-conditioning Control & Picrotoxin $1 \mathrm{mg} / \mathrm{kg}$ & $\mathrm{H}_{2} \mathrm{O}$ & Ethanol & Two Bottle Test & No Aversion \\
E Injection Control & Picrotoxin $1 \mathrm{mg} / \mathrm{kg}$ & Saccharin & Saline & Two Bottle Test & No Aversion \\
\hline
\end{tabular}

ditioning low dose injection of picrotoxin $(0.5 \mathrm{mg} / \mathrm{kg})$, and those in Group $\mathrm{C}$ receiving a preconditioning high dose injection of picrotoxin (1.0 mg/kg, Group C). Procedures for CS consumption and the post consummatory injection were identical to that received by Group A. Groups D and E served as common CTA controls where no contingency was provided between the CS (saccharin) and UCS (ethanol). Group D received regular tap water as the CS, while Group E received a post-consummatory injection of saline. Both groups $\mathrm{D}$ and $\mathrm{E}$ are included due to the possibility that pre-injection of picrotoxin might itself contribute to a change in fluid preference. A single bottle of water was returned to the cage front 30 minutes after conditioning procedures were concluded, and remained until the start of 2-bottle testing 7 days later.

\subsection{Measures}

Picrotoxin's impact on ethanol's UCS potency was assessed via 21 days of two-bottle testing during which the TAP rats were given nearly constant access to one bottle of water and one bottle of saccharin solution. Bottles were weighed daily between 1730 and 1800 EST to determine fluid consumption, with the position of each bottle on the cage front reversed after each weighing. A saccharin preference score (SPS) was calculated by dividing the amount of saccharin consumed by the total amount of fluid consumed: (saccharin/(saccharin + water) $\times 100$ ). Low saccharin consumption (i.e., a low SPS) is indicative of a learned aversion due to its pairing with ethanol.

\section{Results}

Twelve of the animals (5 in Group C, 3 in Group D, and 4 in Group E) administered the high dose of picrotoxin $(1.0 \mathrm{mg} / \mathrm{kg})$ had seizures following preconsummatory injections). Three of these animals died, as did another animal that had received a saline injection, but did not evidence seizure.

\subsection{Weights}

Mean animal weight $( \pm \mathrm{SD})$ prior to conditioning was 337 $\pm 100 \mathrm{~g}$, followed by a mean of $309 \pm 84 \mathrm{~g}$ at the end of the study. A repeated measures analysis of variance (ANOVA) revealed a significant weight decrease over days, $F(1,41)$ $=29.75 ; p<0.001$, as typically seen with short-term fluid deprivation, handling and being subjected to i.p. injections. There were no significant weight loss differences either across groups, $F(4,41)=1.24, p>0.05$, or within groups across days, $F(4,41)=0.91, p>0.05$.

\subsection{Saccharin Preference Scores}

Mean SPSs across days and groups may be viewed in Figure 1. A repeated measures ANOVA revealed a statistically significant group effect, $F(4,41)=4.147 ; p<$ 0.01 and days effect on SPSs, $F(8,339)=3.36 ; p<0.01$. Tukey's post-hoc tests revealed that experimental Groups B and C, administered picrotoxin prior to the ethanolsaccharin pairing, had statistically higher SPSs than the conditioning control Group A ( $p$ 's $<0.05$ ), and similar SPSs to non-conditioning and pseudo-conditioning Groups D and E ( $p$ 's $>0.05$ ). Groups B and C did not statistically differ from each other, $(p>0.05)$, indicating no differential dose response effect. The group $\mathrm{x}$ days interaction was not significant, $F(33,339)=1.24 ; p>$ 0.05 .

\section{Discussion}

Consistent with the primary hypothesis, TAP animals, which normally develop strong alcohol-induced saccharin aversions in the TA paradigm [7], failed to do so in the presence of the GABA antagonist picrotoxin. Results suggest that: 1) picrotoxin can effectively block the aversive component of ethanol, 2) the GABA system plays a role in modulating the motivational (aversive/rewarding) effects of ethanol, and 3) these effects can be elucidated through a classic taste aversion paradigm. Dose-response testing failed to demonstrate a significant difference between $0.5 \mathrm{mg} / \mathrm{kg}$ and $1.0 \mathrm{mg} / \mathrm{kg}$ picrotoxin on saccharin preference, indicating that the GABA receptor complex can be effectively antagonized with a low dose of this substance.

TAP animals receiving pre-conditioning injections of 


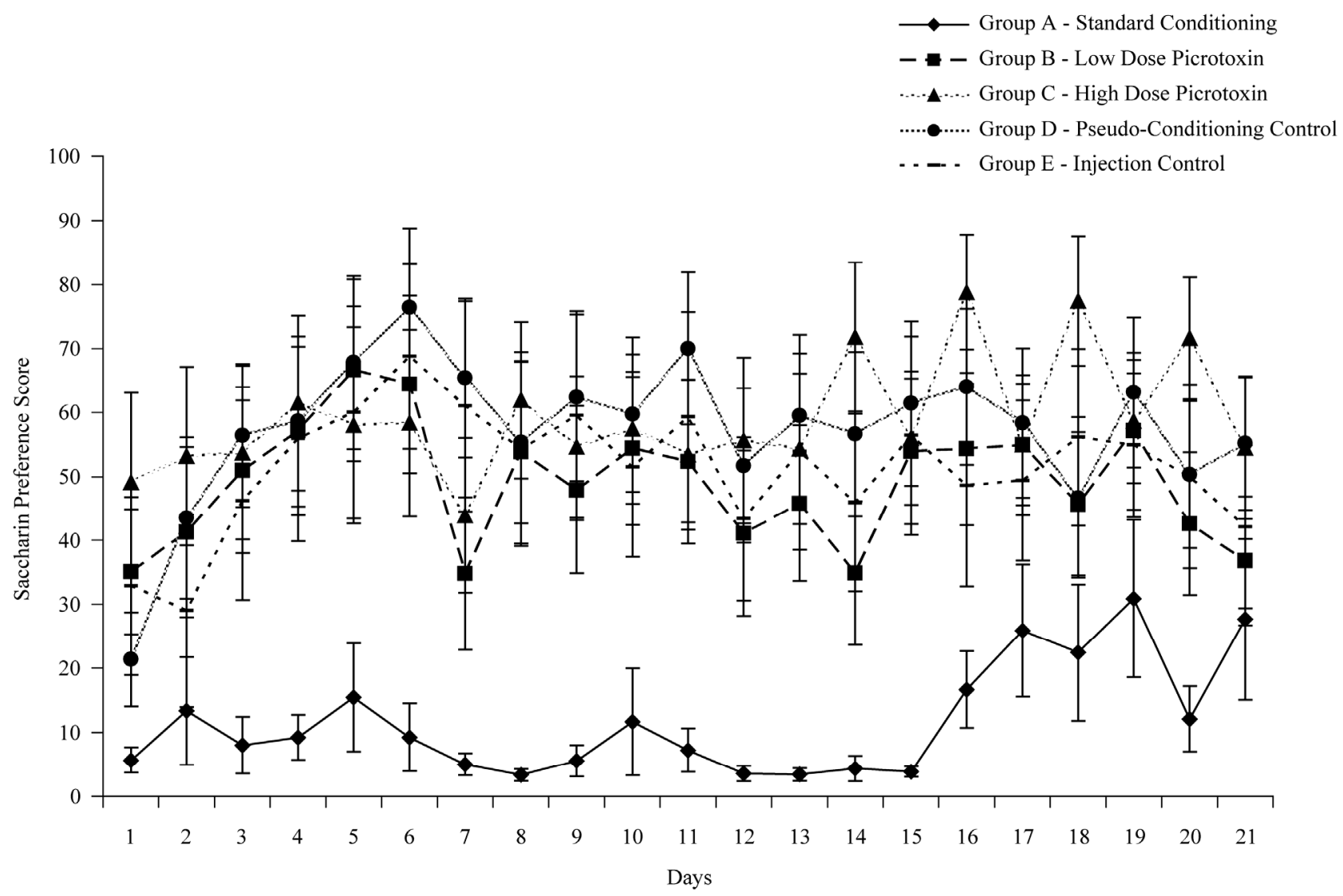

Figure 1. Mean group saccharin preference scores across post-conditioning test days.

picrotoxin (Groups B and C) displayed significantly higher preferences for saccharin compared to the standard conditioning group (Group A) which did not receive a pre-conditioning injection of picrotoxin, and similar saccharin preferences to the pseudo-conditioning and injection control groups (Groups D and E) where no association between ethanol and saccharin was provided. Because TAP rats presumably find ethanol quite aversive (see Group A), the higher saccharin preference scores observed in both Groups B and C suggest that GABA mediates these animals' aversive experience of ethanol, although the exact mechanisms underlying this relationship remain unknown.

Nevertheless, there are at least two testable hypotheses regarding GABA's effect on ethanol motivation in TAP rats. Consistent with prior human studies [23], the experience of an altered state (i.e. being "drunk" or "high") may produce an aversive anxiety and/or panic state in TAP animals. Since picrotoxin has been shown to block the anxiolytic-like and panicolytic-like effects of sodium valproate in animal models [24], it is plausible that picrotoxin may be functioning to alleviate a similar ethanolproduced effect. Another possibility is that picrotoxin's role could involve central GABA-mediated associative processes that link peripheral negative gastrointestinal consequences of ethanol with the sensory attributes of a TA conditioned stimulus, akin to the saccharin solution CS of the present study. From this perspective, the presently reported hindrance with the acquisition of ethanol induced TAs in TAP rats may have resulted from picrotoxin's interference with Garcia's nausea based gut defense system [25].

Current findings corroborate one previous study which showed that picrotoxin can attenuate an ethanol-induced taste aversion in male Long Evans rats [21]. On the other hand, three ethanol self administration studies have demonstrated a blockage of the rewarding effects of ethanol by picrotoxin [26-28]. These mixed findings suggest that the type of procedure used (e.g. self administration vs. CTA) may influence an organism's response to alcohol and picrotoxin —or to GABAergic drugs in general. Risinger and Cunningham [29] have shown that the rewarding and aversive mechanisms of alcohol are under separate sources of genetic control. Prior research with the TAP/TAR lines has also shown that alcohol differentially affects gene expression associated with various neurotransmitter systems-including 5-HT, acetylcholine, and GABA [30]. Future studies should examine the genetic 
basis of ethanol-induced CTAs in more detail, and should examine how picrotoxin affects the rewarding and aversive experience of ethanol consumption.

The marked change in ethanol motivation observed in TAP animals has significant implications for the treatment of alcohol dependence, especially those individuals who elect to receive a CTA procedure as a component of their treatment $[22,31,32]$. Chemical aversion therapy is an effective evidence based, yet underutilized treatment modality for various types of substance dependent patients $[22,32,33]$. The conditioning Group A of the present study highlights both the specifics of its design and implementation, as well as its potency in producing an effect. Chemical aversion therapy, which pairs alcoholic beverages with emetically induced nausea, was developed as a conditioned reflex treatment [34]. However, it is now recognized as a clinical application of the powerful CTA methodlogy [22,32]. Chemical aversion therapy transforms alcohol cravings into alcohol revulsions; since 1940 the treatment has been associated with multiple reports of one-year abstinence rates typically ranging from $60 \%$ to $70 \%$ [22,32-34]. However not all patients are suitable for CTA. For example, it has long been recognized that a small minority of alcohol dependent patients fail to acquire therapeutically effective nausea based CTAs [22,35,36]. A greater understanding of the GABA system as it relates to CTA may serve to aid in the development of pharmacotherapeutic treatments which could enhance the effectiveness of aversion based interventions with TAR patients.

A logical next step in this particular line of work would be to examine the effects of picrotoxin in the TAR line of rats which have been shown to self-administer higher quantities of alcohol than TAP rats [8]. The specific effects of alcohol that TAP rats find aversive may precisely be what the TAR rats find rewarding (e.g., sedation, intoxication, disinhibition). If this hypothesis were true, picrotoxin would presumably render the experience of ethanol in TAR rats far less appealing than usual. Of particular interest here, Lhuintre et al. [37] reported a double blind placebo controlled study in which calcium bis acetyl homotaurine, a GABA agonist, reduced relapses of recently detoxified alcoholics who also participated in three months of outpatient treatment.

Research is also needed to appropriately quantify what constitutes a convulsant dose of picrotoxin in an attempt to 1) minimize the stress of animal subjects used in experimental research and 2) examine if these effects are species or line specific. In prior studies, doses of picrotoxin used in alcohol and TA research have ranged from 0.75 to $2.5 \mathrm{mg} / \mathrm{kg}$ [15], with doses used to purposely induce seizures ranging from 3.0 to $6.0 \mathrm{mg} / \mathrm{kg}$ [38-40]. In the present study, over one third of the animals receiving the $1.0 \mathrm{mg} / \mathrm{kg}$ dose of picrotoxin evidenced seizure, three of which resulted in deaths. It is possible that the TAP line is epilepsy prone-although seizures in this line have not been observed in response to other agents such as cocaine [41] and nicotine [42]. Finally, it would be worth investigating if picrotoxin can have an effect on TAs in the presence of other UCSs. For instance, it is well documented that youths [43] and adults [44] easily acquire TAs to ingestibles that are consumed prior to chemotherapy induced nausea. This could have health implications should nutrition be compromised, especially in children.

In summary, this study demonstrates that a relatively small dose of the GABA antagonist picrotoxin can attenuate the aversive experience of ethanol by TAP rats. These results add further support to the hypothesis that the GABA system is involved in modulating the motivational consequences associated with alcohol exposure. Since there are substantial implications of this research for improving substance abuse treatment; a better understanding of the precise mechanisms of these effects is warranted.

\section{Acknowledgements}

We gratefully acknowledge the assistance of Amy McCord with post-conditioning data collection and entry, and of Kenny Karyadi with editorial feedback.

\section{REFERENCES}

[1] B. Green, D. Kavanagh and R. Young, "Being Stoned: A Review of Self-Reported Cannabis Effects,” Drug and Alcohol Review, Vol. 22, No. 4, 2003, pp. 453-460. doi:10.1080/09595230310001613976

[2] M. Sofuoglu, S. Brown, S. Dudish-Poulsen and D. K. Hatsukami, "Individual Differences in the Subjective Response to Smoked Cocaine in Humans," The American Journal of Drug and Alcohol Abuse, Vol. 26, No. 4, 2000, pp. 591-602.doi:10.1081/ADA-100101897

[3] H. R. Sumnall, J. C. Cole and L. Jerome, "The Varieties of Ecstatic Experience: An Exploration of the Subjective Experiences of Ecstasy," Journal of Psychopharmacology, Vol. 20, No. 5, 2006, pp. 670-682. doi:10.1177/0269881106060764

[4] H. Harwood, "Updating the Economic Costs of Alcohol Abuse in the US: Estimates, Update Methods, and Data,” 2000.

http://pubs.niaaa.nih.gov/publications/economic-2000/alco holcost.PDF

[5] R. D. Myers and J. A. Ewing, "Aversive Factors in Alcohol Drinking in Humans and Animals," Pharmacology, Biochemistry, and Behavior, Vol. 13, Suppl. 1, 1980, pp. 269-277.

[6] R. L. Elkins, “Separation of Taste-Aversion-Prone and Taste Aversion-Resistant Rats through Selective Breeding: 
Implications for Individual Differences in Conditionability and Aversion Therapy Alcoholism Treatment," Behavioral Neuroscience, Vol. 100, No. 1, 1986, pp. 121124. doi:10.1037/0735-7044.100.1.121

[7] R. L. Elkins, P. A. Walters and T. E. Orr, "Continued Development and Unconditioned Stimulus Characterization of Selectively Bred Lines of Taste Aversion Prone and Resistant Rats," Alcoholism: Clinical and Experimental Research, Vol. 16, No. 5, 1992, pp. 928-934. doi:10.1111/j.1530-0277.1992.tb0189

[8] T. E. Orr, J. L. Whitford-Stoddard and R. L. Elkins, "Taste-Aversion-Prone (TAP) Rats and Taste-AversionResistant (TAR) Rats Differ in Ethanol Self-Administration, But Not in Ethanol Clearance or General Consumption,” Alcohol, Vol. 33, No. 1, 2004, pp. 1-7.

[9] S. H. Hobbs, P. A. Walters, E. F. Shealy and R. L. Elkins, "Radial-Maze Learning by Lines of Taste-AversionProne and Taste-Aversion-Resistant Rats," Bulletin of the Psychonomic Society, Vol. 31, No. 3, 1993, pp. 171-174.

[10] C. L. Cunningham, C. M. Gremel and P. A. Groblewski, "Genetic Influences on Conditioned Taste Aversion," In: S. Reilly and T. R. Schachtman, Eds., Conditioned Taste Aversion: Behavioral and Neural Processes, Oxford University Press, New York, 2009.

[11] M. E. Toth, S. Gonda, L. Vigh and M. Santha, "Neuroprotective Effect of Small Heat Shock Protein, Hsp27, after Acute and Chronic Alcohol Administration," Cell Stress and Chaperones, Vol. 15, No. 6, 2010, pp. 807-817. doi:10.1007/s12192-010-0188-8

[12] R. L. Elkins, S. H. Hobbs, G. L. Edwards, G. F. Carl and K. A. Karyadi, "Ethanol-Induced Gene Expression Differences in Heat Shock Protein 27 in Ventral Striatum of Taste Aversion-Resistant Rats," Proceedings of the 34th Annual Re search Society on Alcoholism Annual Meeting, Atlanta, GA, 25-29 June 2011.

[13] E. R. Kendal, J. H. Schwartz and T. M. Jessel, "Priniciples of Neural Science," The McGraw-Hill Company, New York, 2000.

[14] R. W. Olsen, "Picrotoxin-Like Channel Blockers of GABAA Receptors," Proceedings of the National Academy of Sciences USA, Vol. 103, 2006, pp. 6081-6082. doi:10.1073/pnas.0601121103

[15] J. A. Chester and C. L. Cunningham, “GABA(A) Receptor Modulation of the Rewarding and Aversive Effects of Ethanol," Alcohol, Vol. 26, No. 3, 2002, pp. 131-143. doi:10.1016/S0741-8329(02)00199-4

[16] R. G. Hill, M. A. Simmonds and D. W. Straughan, “Antagonism of GABA by Picrotoxin in the Feline Cerebral Cortex,” British Journal of Pharmacology, Vol. 44, 1972, pp. 807-809.

[17] H. Qian, Y. Pan, Y. Zhu and P. Khalili, "Picrotoxin Accelerates Relaxation of GABAC Receptors,” Molecular Pharmacology, Vol. 67, No. 2, 2005, pp. 470-479. doi:10.1124/mol.104.003996

[18] M. A. Simmonds, "Classification of Some GABA Antagonists with Regard to Site of Action and Potency in Slices of Rat Cuneate Nucleus," European Journal of
Pharmacology, Vol. 80, No. 4, 1982, pp. 347-358. doi:10.1016/0014-2999(82)90080-2

[19] A. Takeuchi and N. Takeuchi, "A Study of the Action of Picrotoxin on the Inhibitory Neuromuscular Junction of the Crayfish,” The Journal of Physiology, Vol. 205, 1969, pp. 377-391.

[20] V. Paul, L. Reddy and P. Ekambaram, "Prevention of Picrotoxin Convulsions-Induced Learning and Memory Impairment by Nitric Oxide Increasing Dose of L-Arginine in Rats,” Pharmacology, Biochemistry, and Behavior, Vol. 75, No. 2, 2003, pp. 329-334. doi:10.1016/S0091-3057(03)00084-4

[21] B. R. Smith, R. B. Segal and Z. Amit, "Administration of a GABA Antagonist Selectively Attenuates an EthanolInduced Conditioned Taste Aversion,” Pharmacology, Biochemistry, and Behavior, Vol. 33, 1989, pp. 269-271. doi:10.1016/0091-3057(89)90462-0

[22] R. L. Elkins, "An Appraisal of Chemical Aversion (Emetic Therapy) Approaches to Alcoholtreatment,” Behaviour Research and Therapy, Vol. 29, No. 5, 1991, pp. 387-413.doi:10.1016/0005-7967(91)90123-K

[23] B. J. Cox, G. R. Norton, R. P. Swinson and N. S. Endler, "Substance Abuse and Panic-Related Anxiety: A Critical Review," Behaviour Research and Therapy, Vol. 28, 1990, pp. 385-393. doi:10.1016/0005-7967(90)90157-E

[24] P. A. Dombrowski, L. H. Fernandes and R. Andreatini, "Picrotoxin Blocks the Anxiolytic- and Panicolytic-Like Effects of sodium Valproate in the Rat Elevated T-Maze," European Journal of Pharmacology, Vol. 537, No. 1-3, 2006, pp. 72-76.doi:10.1016/j.ejphar.2006.03.037

[25] J. Garcia, "Food for Tolman: Cognition and Cathexis in concert,” In: T. Archer and L. Nilsson, Eds., Aversion, Avoidance, and Anxiety: Perspectives on Aversively Motivated Behavior, Erlbaum, Hillsdale, 1989.

[26] A. E. Boyle, R. Segal, B. R. Smith and Z. Amit, "Bidirectional Effects of GABAergic Agonists and Antagonists on Maintenance of Voluntary Ethanol Intake in Rats," Pharmacology, Biochemistry, and Behavior, Vol. 46, No. 1, 1993, pp. 179-182. doi:10.1016/0091-3057(93)90338-T

[27] K. L. Nowak, W. J. McBride, L. Lumeng, T. K. Li and J. M. Murphy, "Blocking GABA(A) Receptors in the Anterior Ventral Tegmental Area Attenuates Ethanol Intake of the Alcohol-Preferring P Rat,” Psychopharmacology, Vol. 139, 1998, pp. 108-116. doi:10.1007/s002130050695

[28] N. M. Petry, "Benzodiazepine-GABA Modulation of Concurrent Ethanol and Sucrose Reinforcement in the Rat,” Experimental and Clinical Psychopharmacology, Vol. 5, No. 3, 1997, pp. 183-194. doi:10.1037/1064-1297.5.3.183

[29] F. O. Risinger and C. L. Cunningham, "Ethanol Induced Conditioned Taste Aversion in BXD Recombinant Inbred Mice," Alcoholism: Clinical and Experimental Research, Vol. 22, No. 6, 1998, pp. 1234-1244. doi:10.1111/j.1530-0277.1998.tb0390

[30] R. L. Elkins, G. Edwards, S. H. Hobbs, S. Y. Fei, T. A. Stoming, G. F. Carl, et al., "Ethanol Driven Gene-Ex- 
pression in TAP and TAR Rat Brains,” American Journal of Medical Genetics [Abstract], Vol. 105, 2001, p. 568.

[31] R. L. Elkins, K. R. Dandala and J. L. Whitford, "Patient and Provider Acceptance of Chemical Aversion Substance Dependence Treatments," Proceedings of the 118th Annual American Psychological Association Conference, San Diego, 12-15 August 2009,.

[32] S. Revusky, "Chemical Aversion Treatment for Alcoholism,” In: S. Reilly and T. R. Schachtman, Eds., Conditioned Taste Aversion: Behavioral and Neural Processes, Oxford University Press, New York, 2009.

[33] P. J. Frawley and M. O. Howard, “Aversion Therapies,” In: R. K. Ries, D. A. Fiellin, S. C. Miller and R. Saitz, Eds., Principles of Addiction Medicine, 4th Edition, American Society of Addiction Medicine, Inc., Chevy Chase, 2009, pp. 843-855.

[34] W. L. Voegtlin, "The Treatment of Alcoholism by Establishing a Conditioned Reflex," American Journal of Medical Science, Vol. 199, 1940, pp. 802-810. doi:10.1097/00000441-194006000-00008

[35] R. L. Elkins, “Covert Sensitization Treatment of Alcoholism: Contributions of Successful Conditioning to subsequent Abstinence Maintenance," Addictive Behaviors, Vol. 5, No. 1, 1980, pp. 67-89. doi:10.1016/0306-4603(80)90023-4

[36] W. L. Voegtlin, "Conditioned Reflex Therapy of Chronic Alcoholism; Ten Years' Experience with the Method,” Rocky Mountain Medical Journal, Vol. 44, 1947, pp. 807812.

[37] J. P. Lhuintre, M. Daoust, N. D. Moore, P. Chretien, C. Saligaut, G. Tran, et al., "Ability of Calcium Bis Acetyl Homotaurine, a GABA Agonist, to Prevent Relapse in Weaned Alcoholics,” The Lancet, Vol. 1, No. 8436, 1985, pp. 1014-1016. doi:10.1016/S0140-6736(85)91615-0

[38] R. G. Fariello, R. A. McArthur, A. Bonsignori, M. A. Cervini, R. Maj, P. Marrari, et al., "Preclinical Evaluation of PNU-151774E as a Novel Anticonvulsant,” The Journal of Pharmacology and Experimental Therapeutics, Vol. 285, No. 2, 1998, pp. 397-403.

[39] D. S. Reddy, “Anticonvulsant Activity of the Testosterone-Derived Neurosteroid 3 alpha-Androstanediol," Neuro Report, Vol. 15, No. 3, 2004, pp. 515-518. doi:10.1097/00001756-200403010-00

[40] M. Tan, N. I. Kalyoncu and U. Tan, "Sex Difference in Susceptibility to Picrotoxin-Induced Seizures in Rats Following Octreotide," International Journal of Neuroscience, Vol. 112, No. 8, 2002, pp. 903-911. doi:10.1080/00207450290025914

[41] R. L. Elkins, T. E. Orr, J. L. Rausch, Y. J. Fei, G. F. Carl, S. H. Hobbs, et al., "Cocaine-Induced Expression Differences in PSD-95/SAP-90-Associated Protein 4 and in $\mathrm{Ca}^{2+} /$ Calmodulin-Dependent Protein Kinase Subunits in Amygdalae of Taste Aversion-Prone and Taste AversionResistant Rats," Annals of the New York Academy of Sciences, Vol. 1003, No. 1, 2003, pp. 386-390. doi:10.1196/annals.1300.068

[42] J. W. Sparks, "Nicotine Conditionability in TAP and TAR Rats," Proceedings of the 5th Annual Phi Kappa Phi Student Research and Fine Arts Conference, Augusta, 17 March 2004.

[43] I. L. Bernstein, "Learned Taste Aversions in Children Receiving Chemotherapy,” Science, Vol. 200, No. 4347, 1978, pp. 1302-1303. doi:10.1126/science.663613

[44] I. L. Bernstein and M. M. Webster, "Learned Taste Aversions in Humans,” Physiology \& Behavior, Vol. 25, 1980, pp. 363-366. doi:10.1016/0031-9384(80)90274-7 